\section{ECCOMAS}

\section{Proceedia}

COMPDYN 2021

$8^{\text {th }}$ ECCOMAS Thematic Conference on Computational Methods in Structural Dynamics and Earthquake Engineering M. Papadrakakis, M. Fragiadakis (eds.) Streamed from Athens, Greece, 28 - 30 June 2021

\title{
VISUAL PROGRAMMING FOR MACRO-BLOCK ANALYSIS OF MULTI-STOREY MASONRY BUILDINGS
}

\author{
Elham Mousavian*, Luca U. Argiento, Claudia Casapulla \\ University of Napoli Federico II, Department of Structures for Engineering and Architecture, \\ Via Forno vecchio, 36, 80134, Napoli, Italy \\ \{elham.mousavian,lucaumberto.argiento,casacla\}@unina.it
}

\begin{abstract}
This paper presents a Grasshopper (GH) plugin to evaluate the admissible out-of-plane mechanisms in multi-storey masonry buildings and visually display the possible locations for each admissible mechanism at which the failure can happen. Adopting the macro-block modelling approach, GH components are developed considered a limited number of geometric and construction parameters as inputs that allow the possible mechanisms. These include the quality of the connections between the building walls, applied strengthening devices, and the examined building location within an urban block. Modelling the building, all the potential mechanisms and their possible locations are demonstrated in a user-friendly and readable way. The plugin can finally compute the actual mechanism and its optimised geometry as well as the actual building out-of-plane capacity adopting the limit analysis method.
\end{abstract}

Keywords: 3D Macro-Block Model, Out-of-Plane Behaviour, Limit Analysis, Visual Programming, Grasshopper Plugin. 


\section{INTRODUCTION}

Out-of-plane (OOP) mechanisms can take place in masonry buildings without a box-type behaviour, especially in the peripheral walls of existing buildings, even when they are under low intensities of ground motion [1]. The most recurrent ones are related to simple and complex rocking mechanisms, as well as to flexure mechanisms, as identified and classified by systematic surveys of the typical seismic damages and crack patterns in masonry buildings [2-5]. Post-seismic surveys [2,6] and experimental tests [7] have also identified particular conditions governing the classified OOP mechanisms, including: the quality of the connections between the orthogonal walls as well as the walls and horizontal diaphragms, the roof typology, the positions of the openings and of the building within an urban block. The seismic assessment of historical masonry buildings with respect to OOP mechanisms cannot disregard these aspects, especially when non-linear static and dynamic analysis are employed [8-10] and strengthening interventions [11-13] or dissipative devices are to be designed [14].

Within the simplified approaches to investigate the OOP failure modes in masonry buildings, the kinematic method of limit analysis is one of the most popular and reliable in the literature $[15,16]$. According to it, local mechanisms can be considered as kinematic chains of masonry portions, regarded as rigid macro or micro-block assemblages, interacting through interface elements. In particular, the macro-block model assumes that the general failure involves a number of cracks, which separate the structure into a few rigid macro-blocks, and all the possible relative motions among units (rocking and/or sliding) are concentrated along these cracks $[5,17]$.

However, despite several advantages of the macro-block modelling approach, like being computationally efficient, it normally faces a considerable level of uncertainties, since the given input data for the analysis are simplified into a limited number of parameters. These aspects are well addressed in [2], where the FaMIVE (Failure Mechanism Identification and Vulnerability Evaluation) procedure is introduced to evaluate the most recurrent failure modes in aggregate buildings and to find the optimal option among them. When the advanced macro-block model developed in [5] is adopted, the admissibility of possible mechanisms in aggregate buildings also depends on the involved portions of walls at each storey and on the height ratios between the main building and the adjacent ones, in addition to the position of strengthening devices and the wall connections quality considered by FaMIVE.

Determining the admissible and inadmissible mechanisms for each storey/side of a building is though not very handy and readable using the text-based representations proposed in [2] and [5]. Instead, their graphical visualization would help the evaluator to better assess the reliability of the final solution as well as the other possible alternatives.

To this aim, taking advantage of the 3D visualization [18, 19], this paper presents a novel graphical approach based on the development of a Rhino Grasshopper (GH) plugin. This allows to parametrically model multi-storey masonry buildings and visually check all the potential OOP failure modes and their positions in real time, evaluated according to the work of Casapulla et al. [5]. Using the powerful optimization toolbox, the plugin can also compute the collapse load factors related to each possible mechanism at each storey and visualize the crack pattern of the related OOP mechanism and specifically performs the most likely collapse mechanism configuration and its related (optimal) load factor.

Adopting the concept of visual programming, the developed plugin provides a fast and user-friendly tool for: 1) parametric modelling; 2) visual analysis of all the possible mechanisms in a multi-storey masonry building; 3) computing the minimum load factor among all the possible mechanisms and visualize the related crack pattern; 4) easily linking the modelled building and mechanisms to other analytical software implementations, e.g., 
macro or micro-model finite element [20] and discrete element [21] approaches for further analyses.

In the following, an overview on the typical OOP failure mechanisms and the evaluation process to find the admissible mechanisms at each storey of a building is presented, with an application to the corner failure as an example. Then, the computational implementation of the GH plugin is presented to visually check the admissible and optimized mechanisms in real time.

\section{MODELLING THE OOP FAILURE MODES}

The adopted macro-block model [5] is a 3D portion of walls in a multi-storey masonry building that remains undamaged under the seismic motion and is based on the assumption that the constituent micro-blocks (units) have infinite compressive, tensile and shear strengths. Walls are considered to be single-leaf with the modular masonry units at each storey arranged with the running bond pattern. The contact interfaces between the units have no tensile and finite frictional resistance governed by the Coulomb failure criterion. A horizontal static action as a percentage of dead loads (by means of a load factor) is applied to the centre of mass of each moving macro-block, in addition to all the other external loadings.

Figure 1 shows some of the most recurrent OOP mechanisms for a façade wall of a multistorey building, that are the rocking $\left(\mathrm{M}_{\mathrm{A}}, \mathrm{M}_{\mathrm{B}}\right.$ and $\left.\mathrm{M}_{\mathrm{C}}\right)$ and flexural $\left(\mathrm{M}_{\mathrm{D}}\right.$ and $\left.\mathrm{M}_{\mathrm{E}}\right)$ failures. The onset of each mechanism is represented by advanced formulations considering frictional resistances, which are obtained by the linear kinematic approach of limit analysis, as elaborated in [5].
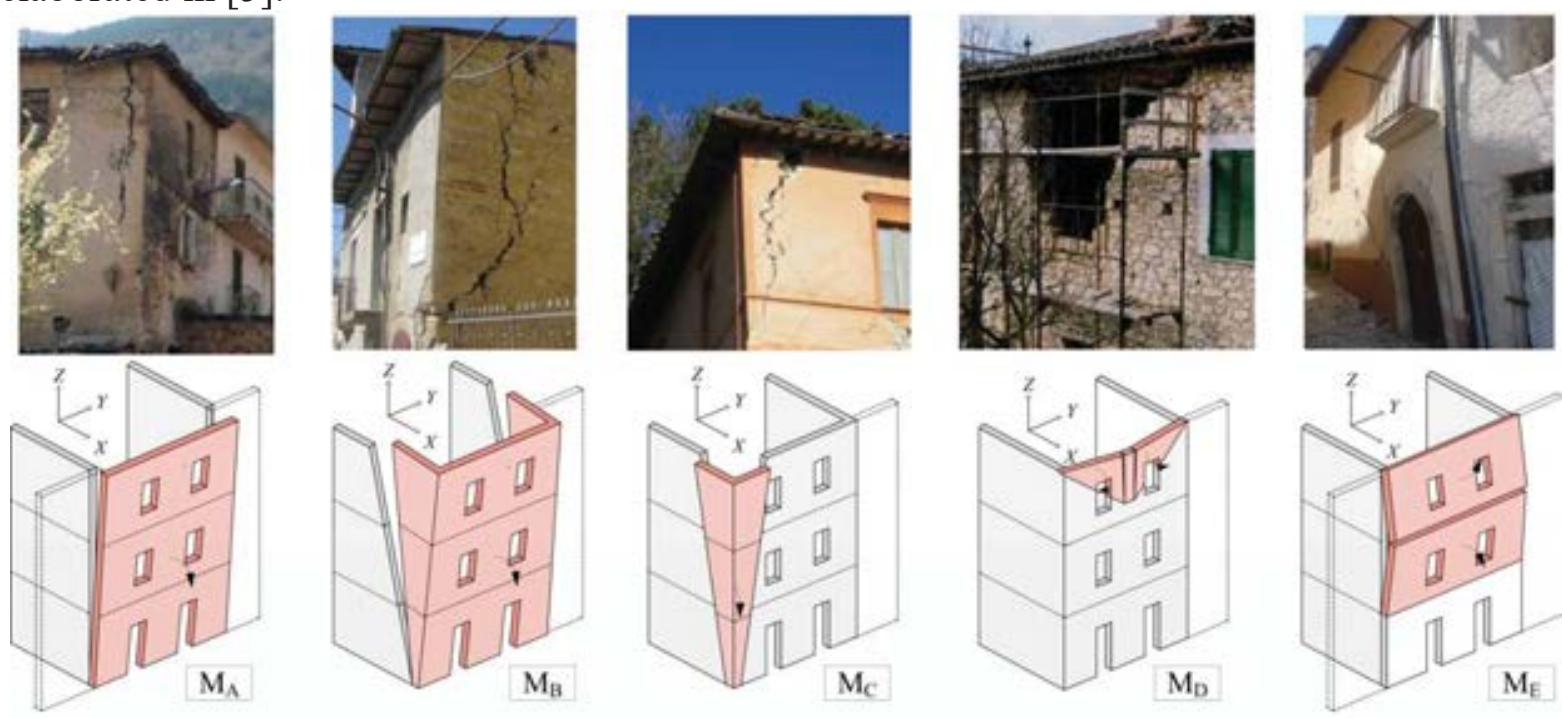

Figure 1: Simple $\left(\mathrm{M}_{\mathrm{A}}\right)$ and compound $\left(\mathrm{M}_{\mathrm{B}}\right)$ rocking walls, rocking corner $\left(\mathrm{M}_{\mathrm{C}}\right)$. Horizontal $\left(\mathrm{M}_{\mathrm{D}}\right)$ and vertical $\left(\mathrm{M}_{\mathrm{E}}\right)$ flexural OOP mechanisms.

\subsection{Parameters governing the admissibility of OOP failure mechanisms}

The admissibility of the failure mechanisms shown in Figure 1 is strictly related to the specific features of the aggregate buildings under study, as highlighted by previous works [2, 3]. The main geometric and construction parameters herein considered are the following ones:

1. Quality of the connection between the façade and sidewalls: this structural feature strongly affects the mechanical integrity of the main building. Poor connection quality between these orthogonal walls usually results in generating the failure modes $\mathrm{M}_{\mathrm{A}}$ and 
$M_{E}$. On the other hand, mechanisms $M_{B}$ and $M_{C}$ can occur in the presence of strong connections, while failure mode $\mathrm{M}_{\mathrm{D}}$ is not affected by this feature.

2. Position of the building within the urban block (Figure 2): it is herein assumed that the position of the building can influence the failure mechanisms $M_{C}$ and $M_{D}$. Besides, the height of the main building with respect to the adjacent buildings is another important aspect, which has not been taken into account in [2] and [3]. In fact, when, e.g., the building is located in a middle position ( $\mathrm{P}_{\mathrm{M}}$ and $\mathrm{P}_{\mathrm{S}}$ cases), mechanism $\mathrm{M}_{\mathrm{C}}$ can only occur if the main building is higher than the adjacent ones, while the horizontal arch failure (mechanism $\mathrm{M}_{\mathrm{D}}$ ) cannot be triggered because the lateral restraints exerted by the adjacent buildings would prevent any lateral displacements.

3. Strengthening devices: Figure 3 shows six configurations of strengthening devices including ring beams and tie-rods. The presence of strengthening devices influences the feasibility of all the mechanisms considered in Figure 1. In fact, all mechanisms can occur in the absence of strengthening devices, except the failure mode $\mathrm{M}_{\mathrm{E}}$ that requires their presence to onset. Since the corner failure in the walls below the tie-rods locations are usually prevented, in the cases of implementing $\mathrm{S}_{\mathrm{RB}}, \mathrm{S}_{\mathrm{T} 3}$, and $\mathrm{S}_{\mathrm{T} 2}$, no mechanism is possible beneath them.

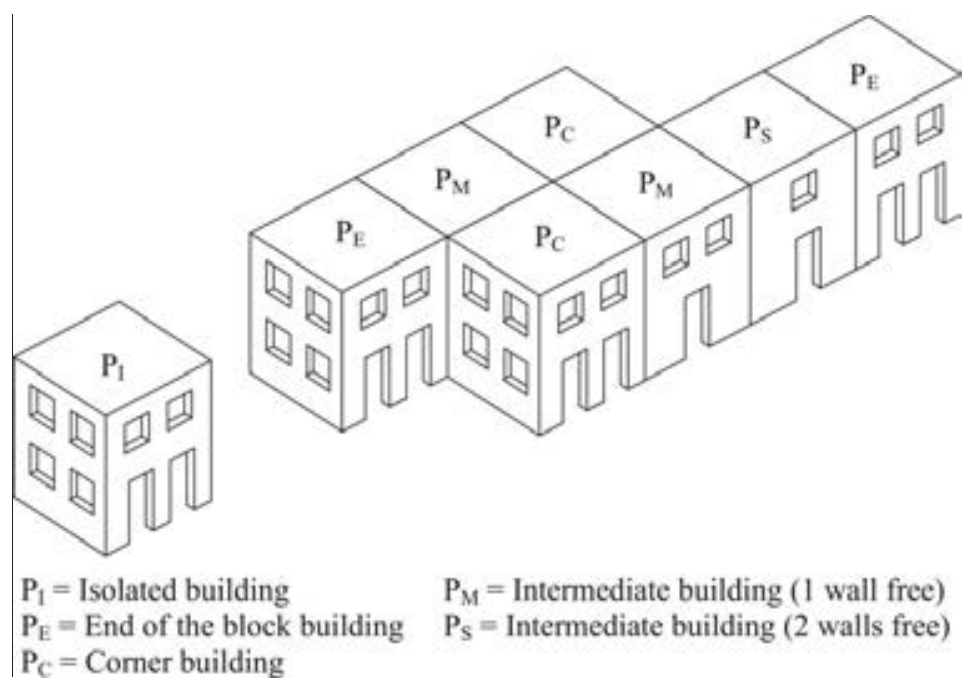

Figure 2: Position of the building within an urban block.
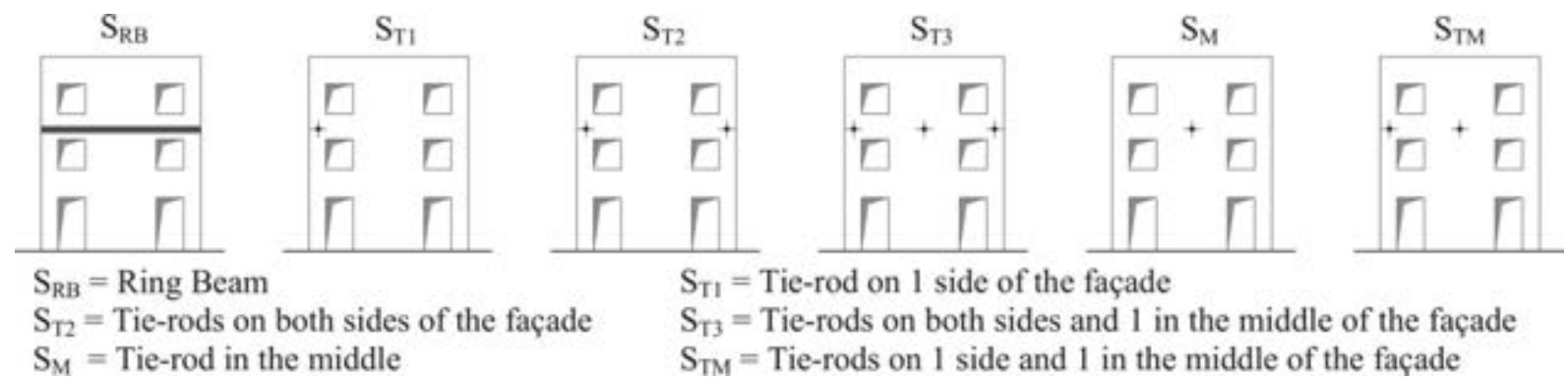

$\mathrm{S}_{\mathrm{T} 2}=$ Tie-rods on both sides of the façade

$\mathrm{S}_{\mathrm{TI}}=$ Tie-rod on 1 side of the façade

$\mathrm{S}_{\mathrm{T} 3}=$ Tie-rods on both sides and 1 in the middle of the façade

$\mathrm{S}_{\mathrm{TM}}=$ Tie-rods on 1 side and 1 in the middle of the façade

Figure 3: Simple layouts of different configurations of strengthening devices.

Each of these three parameters is linked to each mechanism that may occur at a generic storey of a multi-storey building, as displayed in Table 1. If a mechanism is feasible, it will be identified as an admissible mechanism (A), while inadmissible (I) in the opposite case. In some cases, the admissibility of a mechanism depends on the conditions that vary from storey 
to storey, e.g., in the case of different heights of the adjacent buildings it is related to the number of free storeys (D1), while in the presence of strengthening devices (D2) it depends on the highest storey where they are placed.

Obviously, for a given building, the table should be made explicit for each storey, with the admissibility of each possible mechanism depending on the storey properties. Also, to have a more comprehensive evaluation, the table must be extended to each side of the façade wall when, e.g., the storeys number of the adjacent buildings on the right and left sides are different or in the case of having asymmetric strengthening devices ( $\mathrm{S}_{\mathrm{T} 1}$ and $\left.\mathrm{S}_{\mathrm{TM}}\right)$ applications. These aspects would make the table relatively complex and reduce its readability.

To shed more light on this evaluation process, mechanism $\mathrm{M}_{\mathrm{C}}$ (corner failure) is herein chosen as a reference example and how its admissibility is evaluated for a given building is elaborated in the next section.

\begin{tabular}{|c|c|c|c|c|c|c|c|c|}
\hline \multirow[t]{2}{*}{ Mechanism } & \multicolumn{2}{|c|}{ Connection with sidewalls } & \multicolumn{2}{|c|}{$\begin{array}{l}\text { Position of the building } \\
\text { within the urban block }\end{array}$} & \multicolumn{4}{|c|}{ Strengthening devices } \\
\hline & Strong & Weak/Absent & $\mathrm{P}_{\mathrm{I}}-\mathrm{P}_{\mathrm{E}}-\mathrm{P}_{\mathrm{C}}$ & $\mathrm{P}_{\mathrm{M}}-\mathrm{P}_{\mathrm{S}}$ & $\mathrm{NO}$ & $\mathrm{S}_{\mathrm{RB}}-\mathrm{S}_{\mathrm{T} 3}-\mathrm{S}_{\mathrm{TM}}$ & $\mathrm{S}_{\mathrm{T} 1-\mathrm{S}_{\mathrm{T} 2}}$ & $\mathrm{~S}_{\mathrm{M}}$ \\
\hline $\mathrm{M}_{\mathrm{A}}$ & $\mathrm{I}$ & A & A & A & A & D2 & D2 & D2 \\
\hline $\mathrm{M}_{\mathrm{B}}$ & A & I & A & A & A & D2 & D2 & D2 \\
\hline $\mathrm{M}_{\mathrm{C}}$ & A & I & A & D1 & A & D2 & D2 & A \\
\hline $\mathrm{M}_{\mathrm{D}}$ & A & A & A & D1 & A & D2 & A & D2 \\
\hline $\mathrm{M}_{\mathrm{E}}$ & I & A & A & A & I & D2 & D2 & D2 \\
\hline
\end{tabular}

A: admissible possible mechanism

D1: mechanism occurrence depending on the number of stories of the adjacent buildings

D2: mechanism occurrence depending on the highest storey with the strengthening devices

Table 1: Relation between the construction parameters of a building and the feasibility of the mechanisms.

\subsection{Conditions governing the corner failure}

The failure mechanism of a free corner (Mechanism $\mathrm{M}_{\mathrm{C}}$ in Figure 1) is quite common in masonry buildings isolated, positioned at the end of an urban block, or in their free higher storeys. It is characterised by the rocking-sliding of a rigid wedge-shaped macro-block around a hinge point. The corner failure in a masonry building generally involves well-connected masonry walls under orthogonal forces, whose geometry is not known a priori.

Figure 4 shows a 4-storey façade between two adjacent buildings (case $\mathrm{P}_{\mathrm{S}}$ ) with two and one stories on the left and right sides, respectively, having the $\mathrm{S}_{\mathrm{T} 1}$ configuration of strengthening devices at the first floor (Storey no. 4 on the right side of the building). Table 2 shows the possibility of occurrence of mechanism $M_{C}$ at the top-most (Storey no. 1) to the lowest level (Storey no. 4).

As shown in the table, the admissibility of each mechanism is checked (A for being admissible and I for being inadmissible) regarding the connection quality, building position, and the applied strengthening devices separately and, finally, the overall admissibility check is executed for each storey. First of all, according to the first column of the table, mechanism $\mathrm{M}_{\mathrm{C}}$ is a possible failure mode for all storeys since the connections are considered strong enough in both right and left sides of the façade wall. On the other hand, since the adjacent buildings on both sides are shorter than the main building, the corner failure is possible on both sides, at the free storeys only. However, since the adjacent buildings have different heights, the corner failure may have different configurations in either the left or right sides of the building. Similar conditions can occur regarding the applied strengthening device, which 
is also asymmetric. The last column of the table shows the overall admissibility check for the corner failures at each storey of the building.

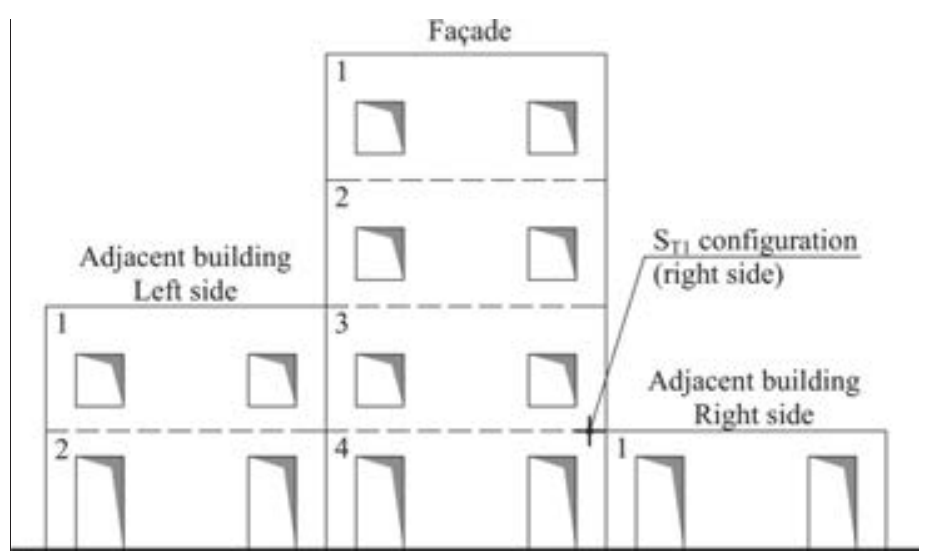

Figure 4: Example of the main building position within an urban block.

\begin{tabular}{|c|c|c|c|c|c|c|c|c|}
\hline \multirow[t]{2}{*}{ Storey } & \multicolumn{2}{|c|}{$\begin{array}{l}\text { Connection with } \\
\text { sidewalls }= \\
\text { Strong }\end{array}$} & \multicolumn{2}{|c|}{$\begin{array}{l}\text { Position of the } \\
\text { building within } \\
\text { the block }=\mathrm{P}_{\mathrm{S}}\end{array}$} & \multicolumn{2}{|c|}{$\begin{array}{c}\text { Strengthening } \\
\text { devices } \\
\text { Devices }=\mathrm{S}_{\mathrm{T} 1} \\
\text { (right side-storey 1) }\end{array}$} & \multicolumn{2}{|c|}{ Final assessment } \\
\hline & $\begin{array}{l}\text { Left } \\
\text { side }\end{array}$ & $\begin{array}{l}\text { Right } \\
\text { side }\end{array}$ & $\begin{array}{l}\text { Left } \\
\text { side }\end{array}$ & $\begin{array}{l}\text { Right } \\
\text { side }\end{array}$ & $\begin{array}{l}\text { Left } \\
\text { side }\end{array}$ & $\begin{array}{l}\text { Right } \\
\text { side }\end{array}$ & Left side & $\begin{array}{l}\text { Right } \\
\text { side }\end{array}$ \\
\hline 1 & A & A & A & A & A & A & A & A \\
\hline 2 & $\mathrm{~A}$ & A & A & A & A & $\mathrm{A}$ & A & A \\
\hline 3 & A & A & I & A & A & A & I & A \\
\hline 4 & A & A & I & I & A & I & I & I \\
\hline
\end{tabular}

A: admissible mechanism

I: inadmissible mechanism

Table 2: The possibility of occurrence of mechanism $\mathrm{M}_{\mathrm{C}}$ for the 4-storey building.

To achieve a comprehensive admissibility evaluation, the same procedure should be developed for all the other mechanisms and the admissibility results gathered all together, which would provide very large tables, even difficult to read. Adding a visual approach would, instead, overcome these difficulties and allow a more user-friendly evaluation.

The following section presents the GH plugin that has been developed to firstly visualise all the possible OOP mechanisms and their locations for a multi-storey building and then to find the actual load factor and the related geometry of the corner failure, used as the reference example.

\section{COMPUTATIONAL IMPLEMENTATION}

A GH plugin has been developed to visually and parametrically demonstrate the potential mechanisms by which a multi-storey masonry building surrounded by adjacent buildings might fail and to compute the actual (optimal) failure mechanism for the building.

The GH plugin has three main functions:

- It enables the user to model the main and adjacent buildings by assigning the number of storeys and the related height. The main building is modelled assigning the length, height, and thickness of the façade and sidewalls, as well as choosing the configuration 
and position of the strengthening devices. The user can parametrically change the input values and observe the updated model in real time.

- Given these geometric inputs, the plugin displays all the potential failure modes (among the selected six mechanisms) that are possible for the model and demonstrates all the possible locations at which the model might fail.

- Given a set of mechanical and external load information, the plugin computes and demonstrates the optimal geometry of the actual failure mechanism and the related load factor.

In the following, these three functionalities are described in detail.

\subsection{Modelling}

The plugin extends the GH environment, a visual programming add-on for Rhinoceros 3D. To develop the plugin, C\# language has been used. The first developed component of the plugin enables the user to visualize the examined buildings and, through parametric change of the inputs, simply observe the updated model in real time. Figure 5 demonstrates all the inputs necessary to construct the main and adjacent buildings. The inputs can be parametrically changed by the user.

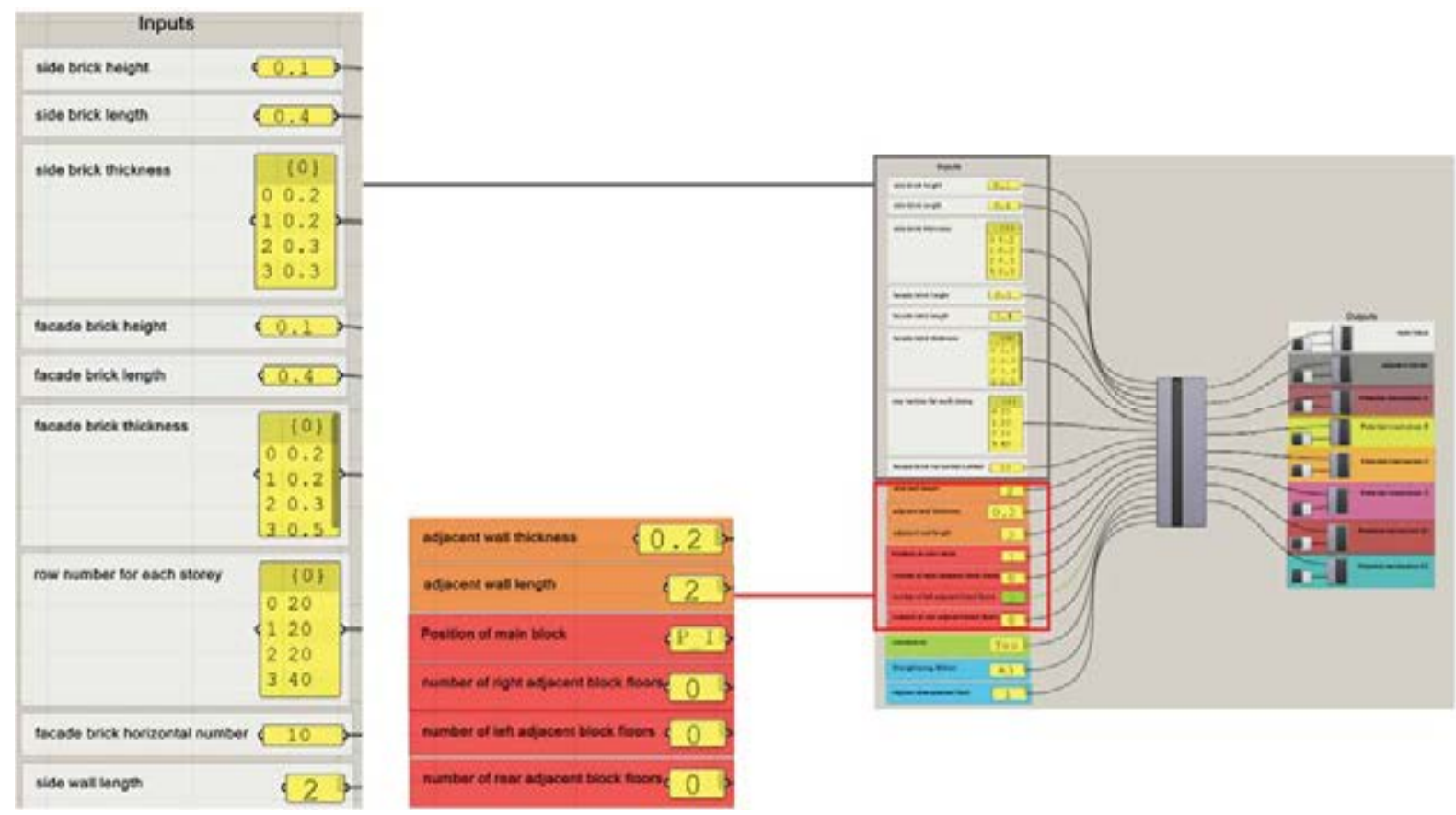

Figure 5. Masonry building modelling component and its inputs.

As examples, Figure 6 illustrates different models developed by different inputs, regarding different storey numbers and heights for the main building as well as different façades, sidewalls lengths and thicknesses. Besides, Figure 7 displays different storey numbers and lengths of the adjacent buildings. 


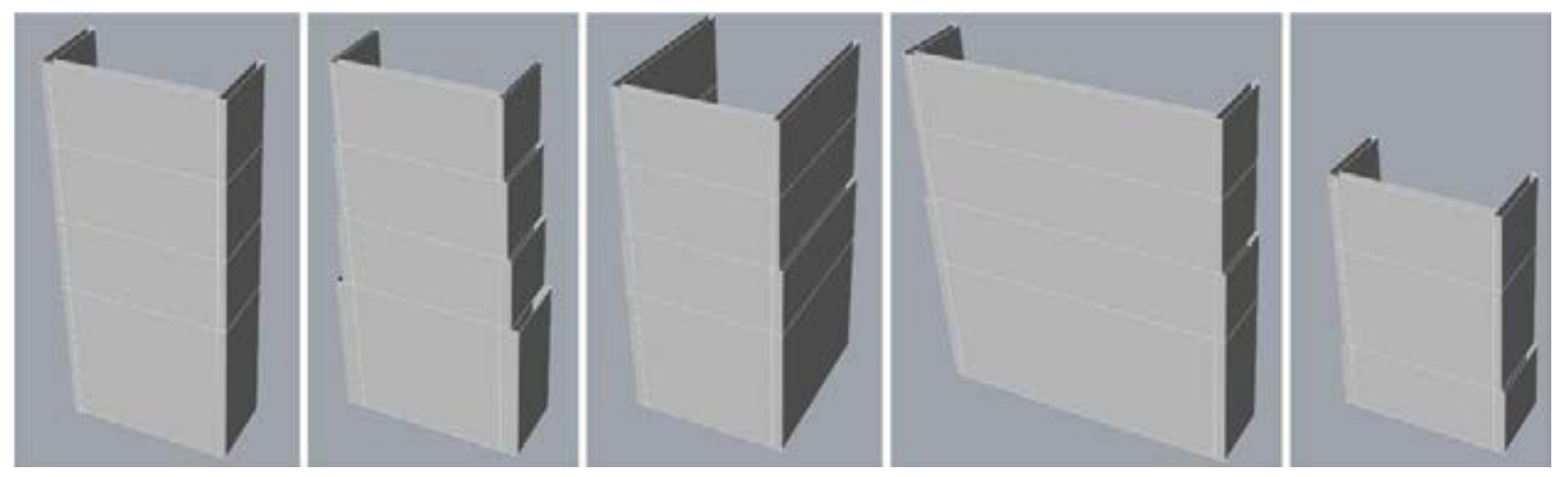

Figure 6. Parametric change of the geometric inputs of the main building.
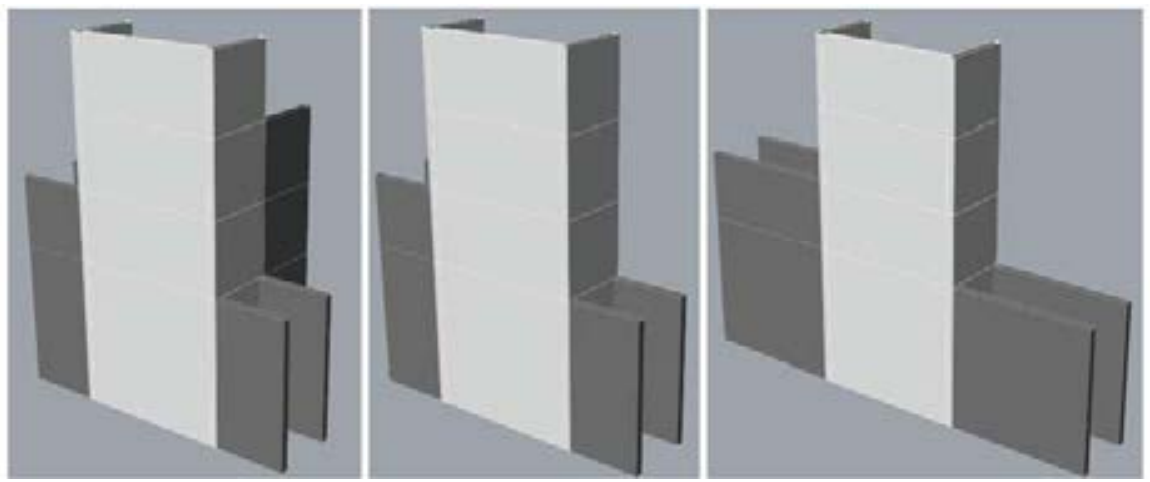

Figure 7. Parametric change of the geometric inputs of the adjacent buildings.

\subsection{Potential mechanism visualization}

Taking advantage of the 3D visualization in GH, the approach elaborated in Section 2 has been adopted to develop a GH component to demonstrate all the possible mechanisms and the locations at which a specific potential failure can occur. Figure 8 shows all the feasible mechanisms and locations among those gathered in Figure 1 and related to the example in Figure 4.

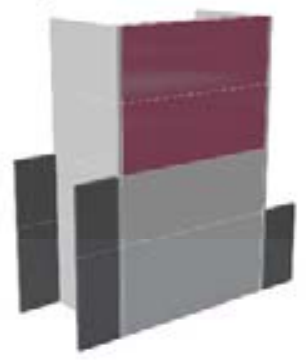

$\mathrm{M}_{\mathrm{A}}$

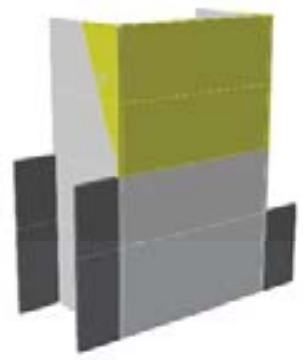

$\mathrm{M}_{\mathrm{B}}$

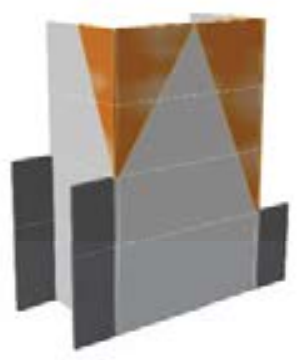

$\mathrm{M}_{\mathrm{C}}$

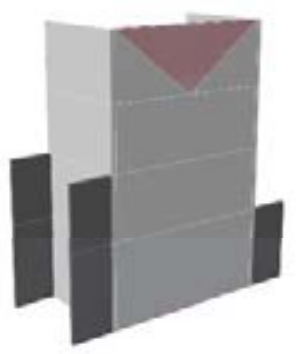

$\mathrm{M}_{\mathrm{D}}$

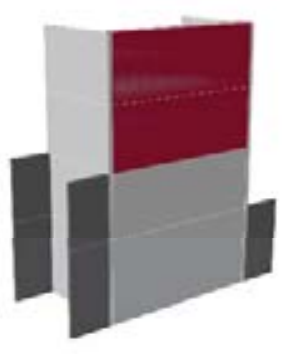

$\mathrm{M}_{\mathrm{E}}$

Figure 8. Different types of potential mechanisms along with all the locations at which the failure is possible.

In particular for the corner failure, Figure 9 visually represents the data reported in Table 2, i.e., all the potential mechanisms that can occur for the main façade presented in Figure 4 and all the possible locations to form a hinge (blue dots) as well as all the possible crack inclinations are visually presented. It is worth highlighting that the crack lines in dry-joint masonry walls have the maximum inclination given by the staggering ratio of the masonry 
units [9]. As can be observed, the readability of the potential failure mechanisms is considerably improved if compared to the data in Table 2.
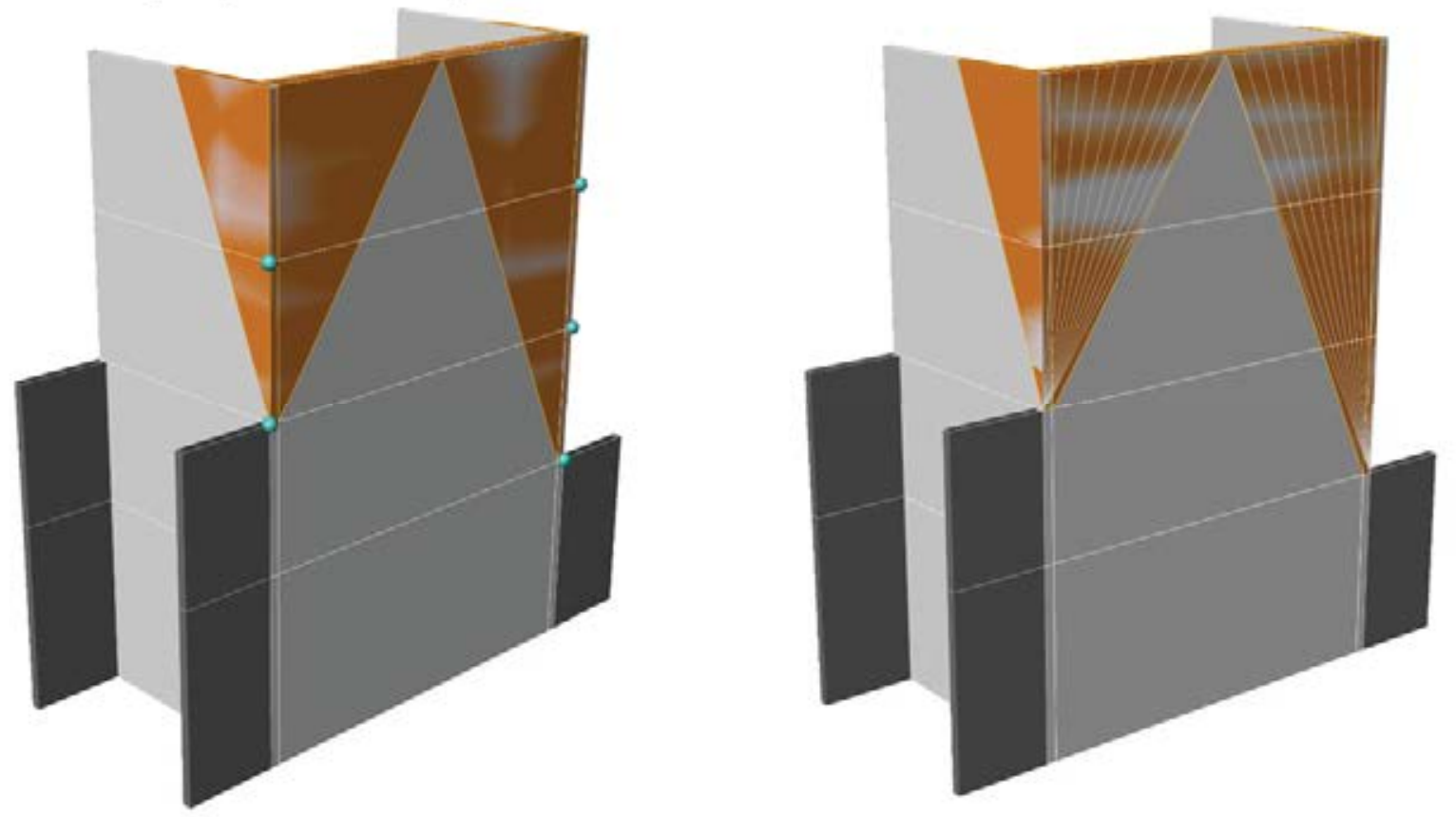

Figure 9. Visualizing all the possible locations for the hinges (blue dots) and crack inclination of mechanism $\mathrm{M}_{\mathrm{C}}$.

\subsection{Actual mechanism visualization}

The plugin can also compute the actual load factor and find the related mechanism shape through managing specific geometric parameters by which the mechanism can be modelled. For example, mechanism $\mathrm{M}_{\mathrm{C}}$ can simply be modelled only by finding the hinge position and the crack inclinations on the façade and sidewalls. The optimization formulations, developed in [5] using Eqs. (10) and (11) of that paper, have been adopted in this work for the assessment of the corner failure. In particular, the geometric variables of the mechanism are the inclinations of the two crack lines for the façade and sidewalls, defining the wedge at each storey where the hinge is placed.

The optimization is executed using MATLAB as the back end. Given the geometric inputs as well as the external loads and the mechanical properties, the developed GH component computes the actual load factor and demonstrates the optimised failure mechanism. For example, Figure 10 demonstrates the actual mechanism $\mathrm{M}_{\mathrm{C}}$ for the building of Figure 4 with its detailed dimensions. As shown in the figure, the expected load factors for the left and right sides of the wall are 0.295 and 0.282 , respectively, while the hinges are formed respectively at the second and first storeys (from the bottom to the top). However, the crack inclinations on the façade wall in both mechanisms are both equal to $26^{\circ}$ and similarly the crack inclinations on both sidewalls are $25^{\circ}$. 


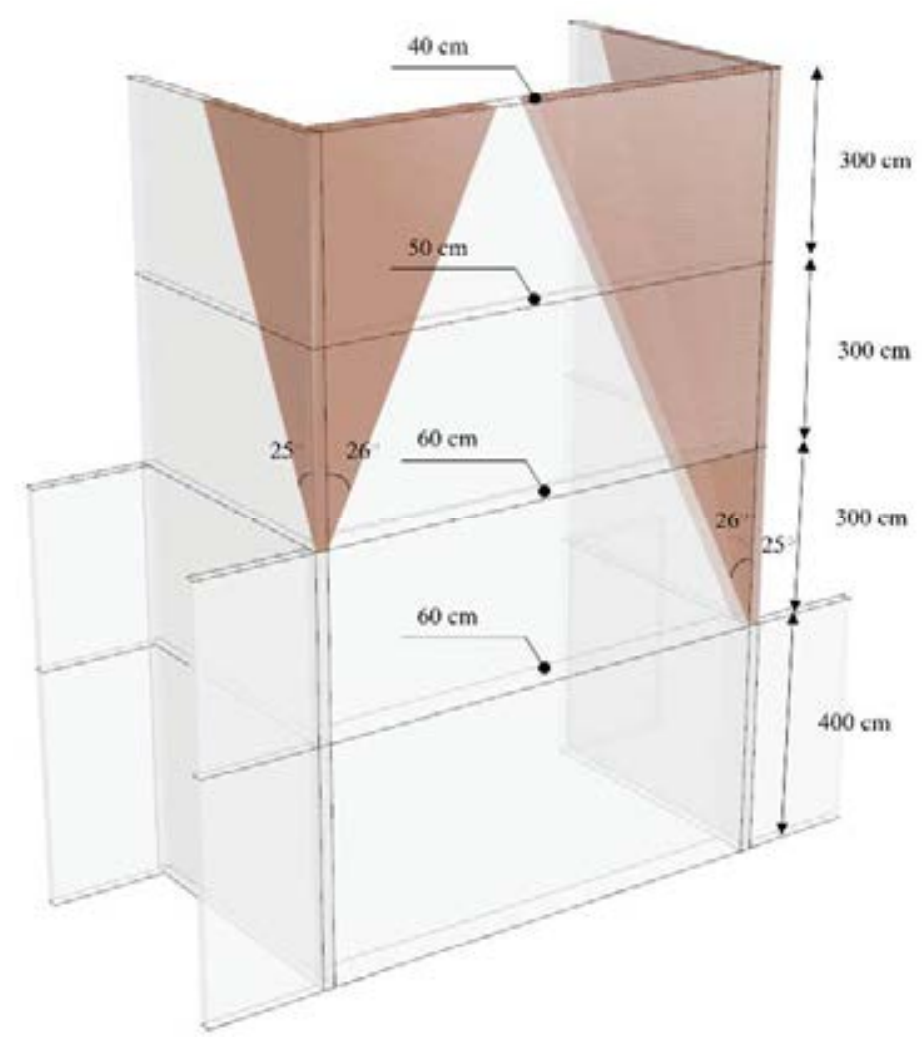

Figure 10. Crack pattern of the corner failures on both sides of the main building.

\section{CONCLUSIONS}

This work deals with the graphic visualization of the seismic vulnerability of historical masonry buildings, isolated or in aggregate, with respect to local failure mechanisms. The mechanical model is based on the kinematic approach of limit analysis developed in [5]. A GH plugin has been developed to parametrically model the main building and visualise all the possible OOP mechanisms and their potential locations, based on the adopted macro-block modelling approach. The plugin has been developed using C\# language.

The visual output data for the potential mechanisms have been compared to similar tables existing in the literature, showing the readability improvements of the visual outcomes comparing to the tables. The plugin can also compute the optimised mechanism and visualize its actual geometry. MATLAB has been used to perform the optimization tasks.

In future works other types of collapse mechanisms will be introduced together with strengthening devices, whether made of traditional or innovative materials. The final goal is to develop a digital framework able to forecast and verify the seismic capacity of the most recurrent local mechanisms, both on the urban scale and building scale.

\section{ACKNOWLEDGMENTS}

This project has received funding from the European Union's Horizon 2020 research and innovation programme under the Marie Sklodowska-Curie Grant Agreement No. 791235. 


\section{REFERENCES}

[1] M.C. Griffith, G. Magenes, G. Melis, L. Picchi, Evaluation of out-of-plane stability of unreinforced masonry walls subjected to seismic excitation. Journal of Earthquake Engineering, 7, 141-169, 2003.

[2] E. Speranza, An integrated method for the assessment of the seismic vulnerability of historic buildings. Ph.D. Thesis, University of Bath (UK), 2003.

[3] D. D’Ayala, E. Speranza, Definition of collapse mechanisms and seismic vulnerability of historic masonry buildings. Earthquake Spectra, 19, 479-509, 2003.

[4] L. Sorrentino, D. D’Ayala, G. de Felice, M.C. Griffith, S. Lagomarsino, G. Magenes, Review of out-of-plane seismic assessment techniques applied to existing masonry buildings. International Journal of Architectural Heritage, 11(1), 2-21, 2016.

[5] C. Casapulla, L.U. Argiento, A. Maione, E. Speranza, Upgraded formulations for the onset of local mechanisms in multi-storey masonry buildings using limit analysis. Structures, 31, 380-394, 2021.

[6] M.L. Puppio, L. Giresini, Estimation of tensile mechanical parameters of existing masonry through the analysis of the collapse of Volterra's urban walls. Frattura ed Integrità Strutturale, 13(49), 725-738, 2019.

[7] P.X. Candeias, A. Campos Costa, N. Mendes, A.A. Costa, P.B. Lourenço, Experimental assessment of the out-of-plane performance of masonry buildings through shaking table tests. International Journal of Architectural Heritage, 11(1), 31-58, 2017.

[8] S. Lagomarsino, S. Cattari, PERPETUATE guidelines for seismic performance-based assessment of cultural heritage masonry structures. Bulletin of Earthquake Engineering, 13(1), 13-47, 2015.

[9] C. Casapulla, L. Giresini, L.U. Argiento, A. Maione, Nonlinear static and dynamic analysis of rocking masonry corners using rigid macro-block modelling. International Journal of Structural Stability and Dynamics, 19(11), (1950137) 1-32, 2019.

[10] L. Giresini, F. Solarino, O. Paganelli, D.V. Oliveira, M. Froli, One-sided rocking analysis of corner mechanisms in masonry structures: influence of geometry, energy dissipation, boundary conditions. Soil Dynamics and Earthquake Engineering, 123, 357-370, 2019.

[11] L. Giresini, Design strategy for the rocking stability of horizontally restrained masonry walls. 6th ECCOMAS Thematic Conference on Computational Methods in Structural Dynamics and Earthquake Engineering (COMPDYN 2017), Rhodes Island, Greece, June 15-17, 2017.

[12] A. Maione, C. Casapulla, F. Ceroni, M. Di Ludovico, A. Prota, Efficiency of injected anchors in connecting T-shaped masonry walls: a modelling approach. Construction and Building Materials, under review, 2021.

[13] A. De Falco, L. Giresini, M. Sassu, Temporary preventive seismic reinforcements on historic churches: numerical modeling of San Frediano in Pisa. Applied Mechanics and Materials, 352, 1393-1396, Trans Tech Publication, 2013.

[14] L. Giresini, F. Solarino, F. Taddei, G. Mueller, Experimental estimation of energy dissipation in rocking masonry walls restrained by an innovative seismic dissipator (LICORD). Bulletin of Earthquake Engineering, 19, 2265-2289, 2021. 
[15] J. Heyman, The stone skeleton. International Journal of Solids and Structures, 2(2), 249-279, 1966.

[16] R.K. Livesley, Limit analysis of structures formed from rigid blocks. International Journal for Numerical Methods in Engineering, 12(12), 1853-1871, 1978.

[17] A. Orduña, P.B. Lourenço, Three-dimensional limit analysis of rigid blocks assemblages. Part I: Torsion failure on frictional interfaces and limit analysis formulation. International Journal of Solids and Structures, 42(18-19), 5140-5160, 2005.

[18] M.F. Funari, S. Spadea, P. Lonetti, F. Fabbrocino, R. Luciano, Visual programming for structural assessment of out-of-plane mechanisms in historic masonry structures. Journal of Building Engineering, 31, 101425, 2020.

[19] E. Mousavian, C. Casapulla, Quantifiable feasibility check of masonry assemblages composed of interlocking blocks. Advances in Engineering Software, 149, art. no. 102898, 2020.

[20] P.B. Lourenço, J.G. Rots, J. Blaauwendraad, Two approaches for the analysis of masonry structures: micro and macro-modeling. Heron, 40(4), 1-28, 1995.

[21] V. Sarhosis, J.V. Lemos, K. Bagi, Discrete element modelling, B. Ghiassi, G. Milani eds. Numerical Modeling of Masonry and Historical Structures: From Theory to Application. Elsevier, Woodhead Publishing Series in Civil and Structural Engineering, 469-501, 2019. 